\title{
Ethical issues arising from a research, technology and development project to support frail older people and their family carers at home
}

\author{
Lennart Magnusson Eng RN MSc DoctCand ${ }^{1}$ and Elizabeth Jane Hanson BA(Hons) Nursing RN PhD ${ }^{2}$ \\ ${ }^{1}$ Department of Health Sciences, University College of Borås, Borås and ${ }^{2}$ ÄldreVäst Sjuhärad Research Centre, \\ Borås, Sweden
}

\author{
Correspondence \\ Lennart Magnusson \\ University College of Borås \\ Department of Health Sciences \\ S-50190 Borås \\ Sweden \\ E-mail: lennart.magnusson@hb.se
}

\begin{abstract}
The present paper provides an overview of the application of the key ethical issues which arose in an EU-funded research, technology and development project, Assisting Carers using Telematics Interventions to meet Older Persons' Needs (ACTION). The primary aim of the ACTION project was to support frail older people and their family carers in their own homes across England, Northern Ireland, the Republic of Ireland, Sweden and Portugal via the use of user-friendly information and communication technology. Ethical guidelines were developed in the project and used as a tool to enable the multidisciplinary project team to increase their awareness of ethical issues in their everyday work, and to act as a useful ethical framework for regular team discussions at international and local meetings across the partner countries. A range of ethical issues arose during the field-study phases of the project when the ACTION services were introduced into a number of families' own homes. It can be argued that these ethical issues reflect factors relating both to the application of research into practice, as well as those relating more directly to the use of new technology by families and care professionals. Key issues centre upon the ethical concepts of autonomy, independence, quality of life, beneficence, non-maleficence and justice, and more specifically, on ethical issues of security, privacy and confidentiality, increased expectations, and withdrawal of the service. This paper is intended to facilitate dialogue and debate in the area of enabling (assistive) technology in home care for older people and their families.
\end{abstract}

Keywords: ethical issues, family carers, older people, research, technology and development project

Accepted for publication 12 May 2003

\section{Introduction}

In order to ensure the optimal use of new enabling (assistive) technology products and services in home care, it is important that research and development projects in this area include an evaluation of the benefits and drawbacks of their use for all the users concerned. By home care, the present authors mean services which are delivered both by healthcare services, such as district nurses, as well as those delivered by social services in the form of assistant home-care workers who carry out personal care, such as assistance with personal hygiene and dressing.

The authors argue that any evaluation should not be purely based on cost calculations. They must rather include a broader and more in-depth analysis of complex issues relating to quality of life (QoL) for the end users of services, as well as job satisfaction for health and social care professionals. Thus, the debate shifts to become an essentially moral one. As Seedhouse (1988) stated, 'work for health is a moral endeavour,' which means that, in the everyday work of care professionals, 
ethical considerations underpin all their interactions with patients and their families. Nowhere does this become more apparent than in home care because care is delivered in the patient and family's own home, rather than the professional's 'home' or territory of the hospital or medical centre. Thus, for the most part, control ultimately rests with the person and family themselves (Ross \& Victor 1999).

\section{Overview of the ACTION project}

The present paper focuses on the key ethical issues arising from an EU-funded research and development technology project, Assisting family Carers through the use of Telematics Interventions to meet Older persons' Needs (ACTION) (1997-2000). The project involved the use of information and communication technology (ICT) in the homes of frail older people and their family carers in Sweden, England, Northern Ireland, the Republic of Ireland and Portugal. The aim was to provide older people and their family carers with information, education and support in relation to their caring situation, via the use of information and communication technology (ICT), in order to improve their autonomy, independence and everyday QoL (Magnusson 2002).

Thus, the primary target group for the ACTION project was older people and their family carers. The ACTION services consisted of multimedia caring programmes, videophone for access to professional carers and other families involved in the project, and Internet access for professional carers and for those families who were interested in using it. The family television was connected to an ordinary computer with a camera attached. For the videophone communication, ISDN2b (this can easily be described as two telephone lines working together to transmit information) was used and the services were navigated by using a remote control (Magnusson et al. 2002).

\section{Research methods employed in the EU ACTION project}

A range of research methods were employed in the project in order to ensure that the voices of the key stakeholder groups were heard. Namely, frail older people, their family carers, a range of professional carers and health and social care providers, as well as representatives from voluntary agencies. Methods included interviews, focus groups and questionnaires with participating families, as well as professional carers and health and social care providers across the partner countries during the development and field study phases of the project. Furthermore, data was collected on an ongoing basis throughout the field study testing periods by means of the use of log diaries by families, and field notes were kept by professional carers and project (research and technical) team members (Magnusson 2000, Magnusson et al. 2002). The ethical issues which are highlighted within the present paper arose largely immediately prior, during and shortly after the field study periods, or verification and demonstration phases of the project, i.e. when the ACTION services were introduced into families' homes $(n=39)$ across the partner countries. These phases involved pilot testing of the ACTION services since it was the first time that the service had been installed in families' own homes. Thus, small sample sizes were deemed to be appropriate (Poulson et al. 1996). Every attempt was made to gain as heterogeneous a sample of families as possible across the partner countries; for example, male and female family carers, those caring for a frail older relative as well as those caring for a relative with cognitive disabilities, and families with differing social backgrounds and formal education. However, it is acknowledged that caution must be exercised when making generalisations from these preliminary findings.

\section{Use of ethical guidelines}

It can be argued that the ethical considerations and dilemmas which may arise in research involving older people do not differ from those associated with any age group. Indeed, to regard family carers and those whom they care for as a special group may be regarded as patronising (Hanson et al. 1998). Nevertheless, because of widespread negative attitudes towards older people and the way in which family carers are frequently taken for granted, ethical considerations may be easily overlooked. For this reason and those outlined above, the EU ACTION project team felt that close attention needed to be given to ensure that the ethical principles relevant to research involving human subjects should be rigorously applied.

In order to help all team members to actualise this important aim, ethical guidelines were developed in the EU ACTION project which built on existing guidelines within the caring professions and the field of engineering, but were also specific to the field of enabling technology (Magnusson \& Barbosa Da Silva 1999). The guidelines served as a useful tool to enable all project members to increase their awareness of ethical issues in their daily work. This was of particular significance because the EU ACTION project was multidisciplinary, and included technicians, and representatives from the business community, none of whom had had any formal prior education in ethics. The guidelines helped the operational management group members to 
be attuned to the personal and communication skills required of a range of consultants hired during the project for a discreet piece of work for a time-limited period, which involved approved and negotiated access, and entry into the research participants' own homes.

The guidelines also served as a useful ethical framework for regular multidisciplinary team discussions which took place in international meetings as well as local meetings across the partner countries. In particular, these discussions helped members to reflect on and discuss, in a supportive environment, ethical dilemmas which arose in the field.

The guidelines consist of a detailed explanation of the ethical principles relevant to research technology and development projects. Namely, respect for human dignity, worth and fundamental rights, autonomy and privacy, confidentiality, informed consent, nonmaleficence, justice, beneficence, and veracity or truthtelling. The explanation of each principle also contains a clear overview of their philosophical origin, as well as practical examples from the ACTION project to illustrate the relevant ethical issues arising within the entire research and development process. Particular emphasis was placed on ethical principles relevant to the exploitation of enabling technology since this element relates more specifically to enabling technology projects and reflects the EU's drive within its Research Technology and Development funding to move from a partially funded project to a fully fledged service or business enterprise (Ballabio \& Moran 1998). The guidelines also contain a succinct discussion of the rationale for the use of ethical guidelines with reference to existing ethical guidelines in the field of health and social care and engineering (Magnusson \& Barbosa da Silva 1999).

\section{Outline of key ethical issues arising from the EU ACTION project}

Against this backdrop, a range of ethical issues arose during the course of the project. The present authors aim to provide an insight into some of the key challenges which the project team experienced when they attempted to apply the ethical guidelines into the real world of applied research. Issues centred upon those of the ethical values of: autonomy, independence, QoL, beneficence, non-maleficence and justice, and more specifically, on issues of security, privacy and confidentiality, increased expectations, and withdrawal of the service. The authors draw upon interview data with participant family carers across the partner countries to substantiate their key arguments and provide direct examples of the specific ethical issues involved.

\section{Autonomy, independence, beneficence, non- maleficence and quality of life: a user-focused perspective}

The ethical concepts of autonomy, independence and QoL acted as the overarching aims of the ACTION project, in particular, to increase the autonomy, independence and QoL of frail older people and their family carers by the use of ICT (Magnusson et al. 2000).

The concept of beneficence was a key consideration, and is related closely to the concept of QoL because the main aim of the project was that the ACTION services would do good by enabling families, at the very least, to maintain and, wherever feasible, improve their everyday QoL by providing them with education, information and support which would directly help them in their individual caring situation. Furthermore, the present authors endeavoured at all stages of the research and development process to ensure, as a minimum, that families would not be privy to any risks either physically or psychologically by taking part in the project, thus drawing on the principle of non-maleficence. To this end, formal ethical approval for the project was secured from local ethical committees in all partner countries involved.

In order to achieve these aims, the project adopted a user-focused philosophy, which means that the views and feedback of the families taking part in the project were of central consideration at all stages of the project. Participating families across the partner countries gave their advice and feedback on a regular basis to help to shape the nature of the ACTION services which were developed and evaluated in the project (Hanson et al. 1999). A number of families who took part in the testing of the caring programmes made direct comments about being actively involved in the project, such as a family carer who took part in a local user group in Northern Ireland:

Thank you for giving me the opportunity of helping with ACTION. Carry on with the good work.

A 69-year-old-family carer in Sweden who had similarly been involved in a local user group to help develop and review the caring programmes, also talked positively about her involvement in the project:

It's been interesting to take part in an international project in which different countries take part - of course the health and social services systems are different, but I can see how ACTION will have more and more in common with the voluntary organisations and charity initiatives that've been introduced in Sweden. I was a bit afraid at first of the idea of accessing information about health issues and care services by using technology, but I've got more and more interested in it. I can even send e-mails to my grandchildren now which is great! 
In their review of enabling technology projects for the Royal Commission on Ageing in the UK, Cowan \& Turner-Smith (1999) highlighted that direct users of services themselves are all too infrequently enabled to have an active voice in the development of new products and services for everyday use. In contrast, they highlighted ACTION as an innovative project which enabled family carers themselves to develop informal support networks with one another from their own homes via the use of the videophone. This finding clearly links to the overall aim of the project, which was to enhance the everyday QoL of older people and their family carers.

\section{Autonomy with regard to the research process}

If we turn to consider more specifically the ethical concept of autonomy, this concept was operationalised as an aim within the research process itself. Project members respected the person's right to self-determination both with regard to the initial decision to participate in the project itself, and subsequently, with regard to the nature of their participation over the course of the project. First, with regard to the initial informed consent process, there were issues which can be deemed to be more specific to home-care technology projects. These centre around the information that was given to potential research participants.

\section{Recruitment and informed consent process: attitudes towards technology}

In all the partner countries within the EU project, it was considered that it was more appropriate for care staff to identify possibly interested families to participate in the project and they were responsible for giving out the information material that had been approved by the local ethical review committee in each country. However, it is interesting to note that, despite the standard information sheet being administered, there remained subtle reasons as to how participants decided whether or not to take part in the project. These reasons relate more widely to views on new technology (Zimmer \& Chappell 1999). First, it can be argued that, for some families, taking part in an EU technology project was rather a privileged and more glamorous situation to be in because staff had chosen that particular family as opposed to another. Secondly, in some situations, it was because of the fact that the family were interested in computers, and felt that it was a golden opportunity to be able to have a computer and other technical equipment in their home, as well as to have educational training to learn how to use it (Hanson et al. 2002). For several families, it was also a potential status symbol: the relatives of the family as well as their neighbours could be invited round to look at and experience it together, in a similar way to when the television was first introduced into private households (Tetley et al. 2000).

\section{Problems with focusing on the technology itself: a case study example}

Because the ACTION project was new and rather exciting, it is possible in some cases that professional carers may well have emphasised, albeit subconsciously, the above aspects of the project such that the focus shifted towards the technology itself. This was perhaps the case with a particular family carer in Sheffield, England, who cared for her elderly father and initially took part in the project because staff had approached her. Healthcare staff knew that she used text television and carried out home shopping via her television set, and they felt that she would enjoy using ACTION in her home. The family carer asked the team to take the equipment out of her home after a short period of time because she felt that it was of no direct use to her in her caring situation - it was in her words 'too little, too late' (Hanson \& Clarke 2000).

This case study was discussed at a local and an international group meeting, and served as a salutary reminder for the ACTION team of the focus of the project as namely one in which technology is simply a tool to help individual families access the education, information and support which they need to help them in their everyday caring situation. In contrast to this case, the majority of families who participated in the project explained that they were happy to use technology if, first and foremost, it was of direct benefit to them in their daily life, if it was easy to use, learn and understand, and if it was loud enough (Magnusson et al. 1999).

\section{Fears that the technology would replace healthcare staff}

At several care settings, a number of staff members did not actively recruit families to the project because of their personal fears that the technology would replace them and act as an alternative to the standard homecare services which they delivered. A professional carer at a participating medical centre in Sheffield argued that 'the whole system [ACTION] can't replace faceto-face contact'. Likewise, many families emphasised the complementary nature of the ACTION project, and argued that it could not and should not replace a home visit.

Despite assurances that ACTION served to act as a complement to professionals' daily work, it was not 
until professionals directly witnessed the positive effect of families' participation in the project that they changed their opinion. For example, a number of professional carers at a medical centre began to see how ACTION could save them time by eliminating routine house calls to provide information and advice so that they could spend more time with seriously ill patients. They also acknowledged that, for those patients living in more rural areas, consultations by videophone might well prove to be more effective than consultation by ordinary telephone (Hanson et al. 2000). Similarly, a welfare rights officer used the videophone for an assessment of an older family carer and his wife who participated in the ACTION project, and found that it was superior to a telephone consultation or an appointment at his office because it enabled him to have a more realistic assessment of the couple in their own home environment (Tetley et al. 2000).

\section{Informed consent process and rights to withdraw: reciprocity}

For some families who took part in the EU project, it involved them testing ACTION in their homes for a period of at least 3 months and a maximum of approximately 9 months. Issues of process consent, as described by Seymour \& Ingleton (1999), became important so that families were asked at every stage of the research and development process whether they would like to continue to take part and their rights to withdraw were emphasised. In practice, it can be argued that it was difficult for the families to say 'no' to being involved in an additional questionnaire or a further interview, to taking part in a local presentation, or to allowing visitors to the project to come and see how ACTION worked in their home. This is probably because, for the most part, families made it clear that they enjoyed carrying out these project activities. As a family carer in Portugal explained:

The ACTION system is good and it was good to be able to take part in work like this. These things are more and more necessary to give support to older people.

Some families also commented on the friendships which developed over time with research team members who visited the families on a number of occasions (e.g. to administer questionnaires relating to the evaluation of the project) as well as with technical members who visited to sort out technical glitches relating to the ACTION system (Hanson et al. 2002). In these situations, it can be argued that rights to withdraw from the project or refusal to take part in particular activities in the project become more difficult for families to achieve. However, in most cases, a reciprocal relationship developed, reflective of the ethical principle of respect for persons, in which the families enjoyed the support of the team members and team members valued the insights which they gained about the nature of family caregiving (Magnusson et al. 2000).

\section{Independence as an ethical issue in the project}

The complementary concept of independence was also operationalised during the project and is also closely linked with the user-focused research model. The aim of the ACTION services was to enable families to have a greater degree of independence or sense of personal freedom within their caregiving situation. By enabling families to have access to education, information and support when they needed it, at a time to suit them and in the convenience of their own home, it allowed families to manage their own caring situation more effectively, thereby increasing their competence, selfconfidence and autonomy, and ultimately, their sense of independence (Magnusson et al. 2002).

The following quotations are illustrative of the views openly expressed by many participant families across the partner countries:

The more information I got, the better I was with her. I can cope better. (Dementia caregiver in England)

ACTION gives you clear instructions about how to turn your husband in bed, for example. It's helped me so that I don't injure myself or my husband. I've increased my self-confidence ... I feel more secure about caring for my husband. (Stroke caregiver in Sweden)

Now I have this here ACTION, I pay all my bills via Internet. That means I don't have to leave my wife to go the bank. (Family carer in Sweden, 82 years old)

After a period of time, some families were able to decide for themselves when to contact care professionals and what form the professionals' support should consist of in order to be of optimal benefit for them. For example, a family carer in the Republic of Ireland commented:

Thinking about your problems before they happen is useful and being better able to cope with them when they happen and preparing for difficult situations, planning ahead, anticipating what situations might arise and planning the possible solutions, I found all that very helpful. It gets you thinking and having telephone numbers handy when you need them quickly. (Magusson et al. 2000).

\section{Dependence on information and communication technology: an ethical issue in the project}

However, whilst increasing their independence in the above respects, it led to a number of families in several 
partner countries becoming dependent on the ACTION services. For example, several family carers experienced the death of a partner whom they had cared for during the course of the project and the videophone served as a valuable source of bereavement support in the form of informal communication with other families involved in the project. In these situations, it was deemed to be ethically inappropriate to withdraw the ACTION equipment from their home. A bereaved family carer in Sweden explained:

If I hadn't have had ACTION and the videophone, I'd have been very isolated. The biggest pleasure I've had from it [ACTION] is Inga [a pseudonym]. We've had such good contact. It's like I've got a sister. You know, even if you've got a big family, when your husband dies, it's a completely different type of loneliness ... So ACTION's been a really big help for me...

However, much discussion in the project centred upon the feasibility of continuing the actual ACTION services beyond the remit of the project because of financial constraints. This issue was raised with participating families at the outset of the project and formed the focus for ongoing user-group discussions at local and international levels about the ways in which ACTION could most effectively be taken forward as a service (Magnusson 2000).

Over this past year in Sweden, some ACTION families have taken the initiative to actively lobby local politicians as well as professionals about the importance of continuing the ACTION service locally. Several families expressed their concern about ACTION being withdrawn from their homes at the end of the project. For example, a bereaved family caregiver admitted:

That's what I am afraid of. That they'll take it [ACTION] away from me.

However, these fears have been allayed recently as two municipalities, namely, Borås and Mark in Sjuhärad, West Sweden (participants in the EU project and the Swedish ACTION project), have formally decided to implement ACTION as part of their mainstream support services for family carers of frail older people (Magnusson 2002).

\section{Privacy, confidentiality and security}

Privacy and confidentiality follow from the principle of autonomy and concern the right of the individual to control access to information about themselves. Considerations regarding security, privacy and confidentiality are recognised as core issues to be discussed and dealt with in an ethically appropriate manner in the research and development of ICT (European Commission 1998).
This is because, in addition to the standard ethical considerations in relation to research involving human subjects, there are additional risk factors associated with the use of computers to store personal data. Within the ACTION project, these risks were not considered high since families did not enter raw data into the computer. However, it was explained that technical logging of their use of the ACTION multimedia programmes and Internet use would be recorded. However, it was emphasised to individuals that the data would remain anonymised and be presented as group data to illustrate overall profiles of use (Emery 1997).

\section{Videophones, and issues of privacy and confidentiality}

Issues of privacy and confidentiality within the ACTION project related more to the use of the videophone and, to a lesser extent, mirror anxieties about privacy in the families' own homes, as reported by Erkert et al. (1993). In this earlier, German-based enabling technology project, participants' concerns about privacy led to the erection of a screen to physically block off the videophone when it was not in use in order to avoid 'big brother' syndrome or 'unjustified paternalism', as coined by Beauchamp \& Childress (2001). Several ACTION families commented that they felt that people could see into their home, as highlighted by a family carer in England when she first had ACTION installed in her home:

I was worried for the privacy of our home ... that's with the camera. (Hanson \& Clarke 2000)

Other families commented that they initially felt self-conscious about their appearance on the screen. As a female family carer in Northern Ireland admitted:

I'm afraid its my own personal pride - it interferes a wee bit on your own personal privacy. It's when the videophone goes on and I look at myself on the screen ... but, again, that's something that through using the ACTION videophone you get used to it ... because you're a carer, you're not always dressed the best and you're not always looking your best. (Magnusson et al. 2000)

However, as in the above carer's situation, after an initial period, most families became accustomed to using the videophone and their initial anxieties wore off as they enjoyed using it to communicate with other families in the project. For example, a family carer in Portugal argued:

The thing that really interests my mother is the videophone my mother talks with other families in the project and it's company for her. She likes it very much. (Magnusson et al. 2000) 


\section{Location of the technology, and issues of privacy and confidentiality}

A number of families considered that the location of the ACTION equipment was a challenge with regard to privacy because, if it was located in a central position in the house, people lacked privacy during a videophone conversation. A family carer in the Republic of Ireland explained:

I'd find this computer would actually be better in a room of its own where you could feel a wee bit of privacy without anybody looking over your shoulder. (Magnusson et al. 2000)

However, several families also felt that it was inappropriate to locate the equipment in a more private part of the house, such as a bedroom. Many families participating in the project did not have a private study area. Thus, location was a key practical as well as ethical consideration in the study (Magnusson et al. 2002).

\section{Suggestion of an 'open-line', and issues of privacy and confidentiality, and non-maleficence}

In the project, the videophone was not activated unless the participants actively rang out themselves or if they actively accepted an incoming call. However, one Swedish family suggested an 'open line' via the videophone for a frail older person living alone or for a family carer caring for a frail older person so that they could take a short break from caring. Professional carers would then be able, via the open line, to check up on the person at regular intervals. For example, to see how the person was feeling and generally managing with their daily life. It can be argued that the open line via the videophone can be used as a security guarantee, and draws on the ethical principle of non-maleficence or preventing harm. Conversely, it can be perceived as an intrusion into the individual's home, and can be construed ethically as an infringement of a person's autonomy and, in particular, an individual's right to privacy, as highlighted above.

Clearly, the open line can be used for different purposes which pose different degrees of morality (Seedhouse 1988). At a higher moral order, it can be used to make it possible for a frail older person to stay safely at home and make them and other family members feel more secure, as suggested by one of the participant Swedish families themselves. However, it can also be used to a lesser moral degree by using it as a tool to make it necessary for the cared-for person to remain at home against her or his will and/or to be monitored regularly by professional carers. The ethical dilemma is solved if the cared-for person is able to give free and informed consent her- or himself.
However, in practice, it is not as clear-cut. Frail older people are often dependent on others for some kind of help, and it can be difficult for them to refuse family members' or professional carers' suggestions regarding care and support. The situation is more complex for those cared-for individuals who are unable to give full informed consent because of illness and/or cognitive impairment. In this situation, the views of the family members are often more likely to be heard and acted upon. Thus, the moral obligation to help according to the principle of beneficence and/or non-maleficence, and justified paternalism would likely be given priority (Pellegrino \& Thomasma 1996).

Despite the fact that formal testing of an open line via the videophone was not carried out during the ACTION project, the issues surrounding the ethical dilemma arising from the principle of non-maleficence versus autonomy with respect to the use of an open-line videophone remains. The debate is growing in Europe largely as a result of demographic factors and the need to find new ways of working to ensure optimal use of diminishing numbers of health and social care workers to support an increasing number of older people in their own homes (Donelly 2002).

\section{The principle of justice and its role in the ACTION project}

The concept of justice was a central consideration in the ACTION project since it relates to issues of fairness with regard to equal access to appropriate home-care services for frail older people and their family carers. Within the project, as was described earlier in the recruitment process, subtle factors came into play with regard to recruitment of families. Due attention was paid to ensure that families were invited to take part who did not have easy access to a computer and had no prior experience of using new technology, rather than focusing on those who had ready computer access and prior experience (Hanson \& Clarke 2000). Indeed, none of the 39 families who took part in the field testing of ACTION in their homes had had prior experience of using a computer.

Later in the project, issues of affordability with regard to mainstream development and implementation of the ACTION services were actively discussed by all those involved in the project with the aim of ensuring social inclusion. This aim is mirrored in EU initiatives with regard to ensuring that the benefits of new technology are accessible to a wide range of groups (Campbell et al. 1999). Evandrou (1998) raised the question of whether lack of access to the Internet in the near future will form another dimension of inequality: 'Will the "connected" and "not connected" be the "haves" and "have nots" of the future?' 


\section{Raising of expectations and information provision: the empowerment process}

An issue arising from the education and information provided via the ACTION multimedia caring programmes was that of raising expectations of families; for example, with regard to information about specific services, as well as about the range of aids and adaptations available in their own home. Professionals in several partner countries expressed concerns that this was likely to be a problem. This was the case for several families who either found an aid to help them with caring for their partner at home, and subsequently, found that it was not possible to obtain because of costs and availability of the product itself, and/or the personnel to install it. Likewise, a family located a particular respite service that was geographically close to them that they later discovered they were unable to qualify for because of the cared-for person's needs (Clarke et al. 1999).

However, more generally, family carers declared that they would prefer to be informed of the nature and range of existing services rather than being 'kept in the dark'. In keeping with the overriding ethical aims of the project, it can be argued that allowing families to become more informed enables and empowers them to begin to ask for the services which they consider are appropriate for their needs (Hanson \& Clarke 2000).

\section{Conclusion}

Thus, to conclude, the present paper has attempted to explain the importance of the use of specific ethical guidelines in enabling technology home-care projects to help a range of personnel involved to carry out ethically responsible work. Examples have been drawn from an EU-funded telematics project, ACTION, to highlight the nature of applied ethical issues which can arise and which are important for consideration by the entire project team; in particular, a range of factors relating to the application of research into practice, as well as those concerned with the use of new technology by families and care professionals. It can be argued that the specific ethical issues raised in this paper need to be examined within the differing contexts of the study itself. Thus, whilst there were overriding similarities regarding the key findings across the partner countries, there were, nevertheless, different health and social care systems in operation, which makes it inappropriate to draw direct comparisons. However, it is the present authors' intention that this paper will facilitate further dialogue and debate, as well as stimulate ideas for further research in the area of applied ethics and enabling technology for older people and their families living in the community.

\section{Acknowledgements}

Our sincere thanks are gratefully extended to all the families and staff who participated in the EU ACTION project, as well as to Professor Inga Wernersson, University of Gothenburg, Gothenburg, Sweden, and Professor António Barbosa da Silva, Missionshögskolan, Stavanger, Norway, for kindly reviewing an earlier draft of this article.

\section{References}

Ballabio E. \& Moran R. (1998) Addressing the Needs and Potential of Older People and People with Disabilities in the Information Society: An RTD Approach for the European Union. EC DGXIII. Telecommunications, Information Market and Exploitation of Research, Brussels.

Beauchamp T.L. \& Childress J.F. (2001) Principles of Biomedical Ethics. Oxford University Press, Oxford.

Campbell P., Dries J. \& Gilligan R. (1999) The Older Generation and the European Information Society: Access to the Information Society. European Institute for the Media, Dusseldorf, and the Netherlands Platform Older People and Europe, Utrecht.

Clarke A., Hanson E., Shewan J., Tetley J. \& McCauley V. (1999) Verification Report. Break from Caring and Planning Ahead Programs. Project deliverable D.10.4 for ACTION DE 3001, unpublished report.

Cowan D. \& Turner-Smith A. (1999) The Role of Assistive Technology in Alternative Models of Health Care for Older People. Appendix 4. Research, Vol. 2. With Respect to Old Age: Long Term Care-Rights and Responsibilities. The Stationery Office, London.

Donelly M. (2002) Workers move across borders - Do services also move? Plenary session presentation at the European Home Care Seminar, Helsinki, 5-7 May 2002.

Emery D. (1997) Technical Standards and Specifications. Project deliverable D.05.1 for ACTION DE 3001, unpublished report.

Erkert T. \& Robinson S. (1993) An Application of Videotelephony to Maintain the Quality of Life of Elderly People with Special Needs. In: B. Glastonbury (Ed.), Human Welfare and Technology, pp. 96-106, Van Gorcum, Assen.

European Commission (1998) Green Paper on the Convergence of the Telecommunications, Media and Information Technology Sectors, and the Implications for Regulation, Towards an Information Society Approach. COM (97)623. European Commission, Brussels.

Evandrou M. (1998) Great expectations: social policy and the new millennium elders. In: M. Bernard \& J. Phillips (Eds) The Social Policy of Old Age, pp. 281-283. Centre for Policy on Ageing, Kent.

Hanson E. \& Clarke A. (2000) The role of telematics in assisting family carers and frail older people at home. Health and Social Care in the Community 8 (2), 129-137.

Hanson E., Magnusson L., Oscarsson T. \& Nolan M. (2002) Benefits of IT for older people and their carers. British Journal of Nursing 11 (13), 867-874.

Hanson E., Shewan J., Tetley J. \& Clarke A. (2000) Focus group findings of cost-benefit considerations by health and social care professionals in Sheffield. In: H. Berthold (Ed.) The ACTION System, Evaluation of the Outcome of the Project, the 
Telematics Applications and Technical System in Relation to Cost-Benefits and Cost-Effectiveness. Project Deliverable D.11.9 for ACTION DE 3001, unpublished report.

Hanson E., Tetley J. \& Bradshaw A. (1998) A Functional Specification for Programmes for Respite Care Choice and Long Term Planning. Project deliverable D.07.2 for ACTION DE 3001, unpublished report.

Hanson E., Tetley J. \& Clarke A. (1999) A multimedia intervention to support family caregivers. Gerontologist 39 (6), 736-741.

Magnusson L. (2000) Final Report - The ACTION Project. ACTION DE 3001, unpublished report.

Magnusson L. (2002) Tbe swedish ACTION Project - Final Report. The Ministry of Health and Social Affairs, Stockholm.

Magnusson L. \& Barbosa da Silva A. (1999) Ethical guidelines for information and communication technology projects - the rationale of an ethical guideline for the application of telematics in health and social care. In: C. Buhler $\&$ H. Knops (Eds) Assistive Technology on the Threshold of the New Millennium, pp. 696-702. IOS Press \& OHMSA, Amsterdam.

Magnusson L., Berthold H., Chambers M., Hanson E., Brito L. \& Daly T. (1999) Carers tap into the information highway. Nursing Times 95 (42), 48-50.

Magnusson L., Hanson E. \& Ljunbgerg C. (2000) Evaluation of the Outcome of the ACTION Project, the Telematics Applications and Technical System in Relation to Maintaining the Autonomy, Independence and Quality of Life for Frail Older Persons and
Their Informal Carers. Project deliverable D.11.7 for ACTION DE 3001, unpublished report.

Magnusson L., Hanson E., Brito L., Berthold H., Chambers M. \& Daly T. (2002) Supporting family carers through the use of information technology - the EU project ACTION. International Journal of Nursing Science 39 (4), 369-381.

Pellegrino E.D. \& Thomasma D.C. (1996) The Christian Virtues in Medical Practice. Georgetown University Press, Washington, DC.

Poulson D., Ashby M. \& Richardson S. (Eds) (1996) USERfit. A Practical Handbook on User-centred Design for Assistive Technology. ECSC-EC-EAEC, Brussels-Luxembourg.

Ross F.M. \& Victor R. (1999) Primary health care and older people. In: S. Redfern \& F. Ross (Eds) Nursing Older People, 3rd edn, pp. 3-8. Churchill Livingstone, Edinburgh.

Seedhouse D. (1988) Ethics: The Heart of Health Care. John Wiley \& Sons, Chichester.

Seymour J.E. \& Ingleton C. (1999) Ethical issues in qualitative research at the end of life. International Journal of Palliative Nursing 5 (2), 65-73.

Tetley J., Hanson E. \& Clarke A. (2000) Older people, telematics and care. In: A. Warnes, L. Warren, L. \& M. Nolan (Eds) Care Services for Later Life, Transformations and Critiques, pp. 243-258. Jessica Kingsley Publishers, British Society of Gerontology, London.

Zimmer Z. \& Chappell N. (1999) Receptivity to new technology among older adults. Disability and Rehabilitation 21 (5/6), 222-230. 